\title{
Development of a Deployable Nonmetallic Boom for Reconfigurable Systems of Small Spacecraft
}

\author{
Fredrik Rehnmark ${ }^{1}$ \\ Lockheed Martin Mission Services, Houston, Texas, 77058 \\ Mark Pryor ${ }^{2}$ \\ ATK Mission Systems Group, San Diego, California, 92121
}

Buck Holmes $^{3}$, Dr. David Schaechter ${ }^{4}$, Dr. Nelson Pedreiro ${ }^{5}$

Lockheed Martin Advanced Technology Center, Palo Alto, California, 94304

and

Dr. Connie Carrington ${ }^{6}$

NASA Marshall Space Flight Center, Huntsville, Alabama, 35812

\begin{abstract}
[Abstract] In 2005, NASA commenced Phase 1 of the Modular Reconfigurable HighEnergy Technology Demonstrator (MRHE) program to investigate reconfigurable systems of small spacecraft. During that year, Lockheed Martin's Advanced Technology Center (ATC) led an accelerated effort to develop a 1-g MRHE concept demonstration featuring robotic spacecraft simulators equipped with docking mechanisms and deployable booms. The deployable boom built for MRHE was the result of a joint effort in which ATK was primarily responsible for developing and fabricating the Collapsible Rollable Tube (CRT patent pending) boom while Lockheed Martin designed and built the motorized Boom Deployment Mechanism (BDM) under a concurrent but separate IR\&D program. Tight coordination was necessary to meet testbed integration and functionality requirements. This paper provides an overview of the CRT boom and BDM designs and presents preliminary results of integration and testing to support the MRHE demonstration.
\end{abstract}

\section{Nomenclature}

$E\left(E^{\prime}\right) \quad=$ Young's modulus (effective $\mathrm{E}$ for wide beams in bending)

$v \quad=$ Poisson's ratio

$b \quad=$ width of rectangular cross section (Neg'ator ${ }^{\circledR}$ spring)

$t=$ thickness of rectangular cross section (Neg'ator ${ }^{\circledR}$ spring and boom)

$D \quad=$ flexural rigidity

$d_{s} \quad=$ diameter of boom storage spool

$d_{b} \quad=$ diameter of fully deployed boom

$L \quad=$ length of boom when fully deployed

$x \quad=$ length of deployed section of boom

$\theta \quad=$ rotation of boom storage spool from boom stowed starting position

$d_{l} \quad=$ fabricated diameter of Neg'ator ${ }^{(0)}$ spring $\approx$ diameter of spring storage drum

$d_{2} \quad=$ diameter of Neg'ator ${ }^{\circledR}$ spring output drum

\footnotetext{
${ }^{1}$ Project Engineer, Mechanisms Group - SEI Orion Program, 2400 NASA Pkwy

${ }^{2}$ Project Engineer, Technology Group, 9617 Distribution Ave

${ }^{3}$ Mechanical Engineer, Opto Mechanical Group, O/ABDS, B/201, 3251 Hanover St

${ }^{4}$ LM Fellow, Precision Pointing and Controls, O/ABFS, B/201, 3251 Hanover St, Associate Fellow AIAA

${ }^{5}$ Director, Science and Technology, O/ABAS, B/201, 3251 Hanover St

${ }^{6}$ Aerospace Engineer, Advanced Sensors, EV21, Marshall Space Flight Center
} 
$T_{r} \quad=$ torque developed in retraction spring subassembly

$U_{\text {boom }} \quad=$ total strain energy stored in spooled boom

$U_{\text {spring }}=$ total strain energy stored in retraction spring subassembly

\section{Introduction}

T AUNCH vehicle payload capacity and the launch environment represent two of the most operationally limiting constraints on space system mass, volume, and configuration. Large-scale space science and power platforms as well as transit vehicles have been proposed that greatly exceed single-launch capabilities. Reconfigurable systems launched as multiple small spacecraft with the ability to rendezvous, approach, mate, and conduct coordinated operations have the potential to make these designs feasible. A key characteristic of these proposed systems is their ability to assemble into desired formations.

While flexible and sparse formations may be realized by groups of spacecraft flying in close proximity, flyers physically connected by active structural elements could continuously exchange power, fluids, and heat (via fluids). Configurations of small spacecraft temporarily linked together could be sustained as long as needed with minimal propellant use and reconfigured as often as needed over extended missions with changing requirements. For example, these vehicles could operate in extremely compact configurations during boost phases of a mission and then redeploy to generate power or communicate while coasting and upon reaching orbit.

In 2005, NASA funded Phase 1 of a program called Modular Reconfigurable High-Energy Technology Demonstrator (MRHE) to investigate reconfigurable systems of small spacecraft. MRHE was aligned with NASA's 2004 Vision for Space Exploration under the Human and Robotic Technologies (H\&RT) Space Exploration Initiatives (SEI) Intramurals. The primary objective of MRHE was to mature technologies for future development of a modular, 100 kilowatt-class electric propulsion spacecraft suitable for on-orbit assembly and reconfiguration. The MRHE team was led by NASA's Marshall Space Flight Center and included Lockheed Martin's Advanced Technology Center (ATC) in Palo Alto and its subcontractor, ATK. Lockheed Martin's task in Phase 1 was to develop an MRHE concept demonstration in a relevant 1-g environment to highlight a number of requisite technologies.

Modular, high-energy, solar-powered spacecraft present particular challenges in assembly, power distribution, thermal management, and survivability in radiation environments. The MRHE spacecraft concept consisted of identical solar-powered modules, each equipped with an electric propulsion system, assembled in a reconfigurable arrangement. A configuration trade performed in Phase 1 resulted in the proposed spacecraft assembly concept shown in Fig. 1.

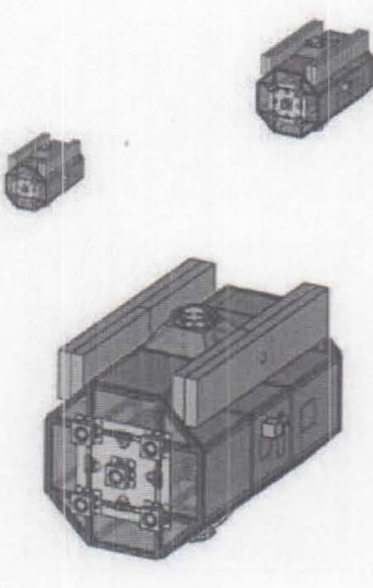

1. Multiple Launches

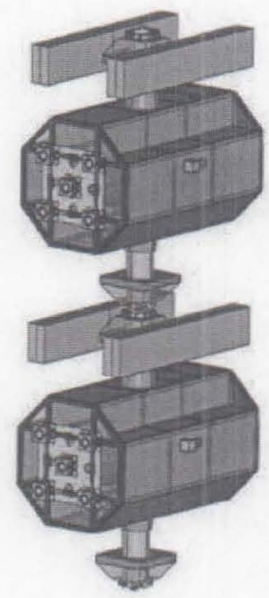

2. Rendezvous \& Docking

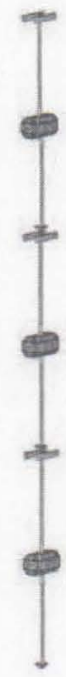

3. Deploy Booms

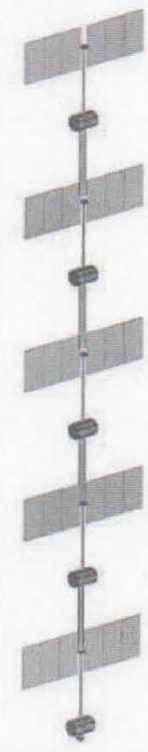

4. Deploy Solar Arrays

Figure 1. MRHE solar electric propulsion transport vehicle concept. 
In Phase 1 of the MRHE program, Lockheed Martin devised and conducted an automated space system assembly demonstration featuring multipurpose free-floating robots representing spacecraft in the newly built Controls and Automation Laboratory (CAL) at the ATC. ${ }^{1}$ The CAL lab features a $12^{\prime} \times 24^{\prime}$ granite air-bearing table and an overhead simulated starfield. Among the technologies needed for the concept demonstration were mechanical interfaces allowing the spacecraft to dock and deployable structures allowing for adjustable separation between them. The decision to use a spooling boom for this purpose was motivated by the MRHE Phase 1 design goals reproduced in Table 1a.

Table 1a. MRHE Phase 1 Design Goals: Deployable Structure.

\begin{tabular}{|l|l|c|c|}
\hline & Description & Value & Units \\
\hline S1 & Number of Deploy/Stow Cycles & $>100$ & cycles \\
\hline S2 & Bending Stiffness (EI)* & 400 & $\mathrm{Nm}^{2}$ \\
\hline S3 & Fully Deployed Length & 2.0 & meters \\
\hline S4 & Transition Region Length & 0.2 & meters \\
\hline S5 & Surface Finish & non-reflective & none \\
\hline
\end{tabular}

* bending stiffness applies to both fully and partially deployed structure

The goals listed in Table $1 \mathrm{~b}$ drove the design of the deployment mechanism.

Table 1b. MRHE Phase 1 Design Goals: Deployment Mechanism.

\begin{tabular}{|l|l|c|c|}
\hline & Description & Value & Units \\
\hline M1 & Position Control & motorized deploy/retract & none \\
\hline M2 & Position Maintenance & $\begin{array}{c}\text { unpowered } \\
\text { (non-backdriveable) }\end{array}$ & none \\
\hline M3 & Deployment Speed & adjustable, up to 5 & $\mathrm{cm} / \mathrm{sec}$ \\
\hline M4 & Packaging Envelope, Width & $\leq 14.0$ & $\mathrm{~cm}$ \\
\hline M5 & Packaging Envelope, Height & $\leq 12.9$ & $\mathrm{~cm}$ \\
\hline
\end{tabular}

\section{Background}

Deployable structures are so widely employed in spacecraft that a taxonomy may be developed. Bowden classifies them broadly into hinged, linear, surface, and volume deployment devices. ${ }^{2}$ Both telescoping and tubular (i.e., spooling) booms are examples of linear deployment devices.

Spooling booms have been part of NASA's space exploration program since the development of the Viking Mars lander with its extending soil sampling arm. The STEM ${ }^{3}$ and BI-STEM ${ }^{4}$ have been commercially available for decades as off-the-shelf linear actuator modules for flight applications. Traditional spooling boom materials include stainless steel and $\mathrm{BeCu}$ but, increasingly, nonmetallic booms are finding application, as well [http://www.rolatube.com/update/index.htm]. Carbon Fiber Reinforced Plastics (CFRP) and other composite materials are attractive due to the high stiffness and strength to weight ratios that may be achieved and the material's versatility in production and fabrication techniques. ${ }^{5}$ Fiber orientations in the laminate can be controlled during fabrication to yield nonmetallic booms with superior thermal stability ${ }^{6}$ and interesting structural properties. ${ }^{7}$ Deployment strategies depend on the application and range from retractable, motorized devices ${ }^{8}$ to unpowered solutions making use of the strain energy stored in the spooled configuration. ${ }^{9}$

The deployable boom built for MRHE was the result of a joint effort in which ATK was primarily responsible for developing and fabricating the boom while Lockheed Martin designed and built the motorized Boom Deployment Mechanism (BDM) under a concurrent but separate Internal Research and Development (IR\&D) program. The three $6.35 \mathrm{~cm}$ diameter, $2.34 \mathrm{~m}$ long booms delivered by ATK employ Collapsible Rollable Tube (CRT - patent pending) technology developed by ATK for Lockheed Martin during a previous collaboration. ATK refined this technology to generation CRT 2.5i for MRHE. In Bowden's taxonomy, CRT booms fall somewhere between interlocking and lenticular booms in performance and complexity.

\section{Collapsible Rollable Tube (CRT ${ }^{\mathrm{TM}}$ )}

\section{A. Technical Summary}

Figure 2 shows one of the CRT booms in its low energy state (i.e., unrolled and unflattened). The boom is assembled from two cylindrical half-shells consisting of $0.33 \mathrm{~mm}$ thick CFRP laminate material joined by metal 
hinges. It weighs approximately $64 \mathrm{~g} / \mathrm{m}$, less than half the linear density of a metallic boom of comparable stiffness. Another benefit of the CRT boom is its ability to support torsional loads, a weakness of booms with simpler overlapping geometries. Mounting holes are cut on opposite ends of the boom to allow installation of the MRHE docking probe and the BDM storage spool clamp.

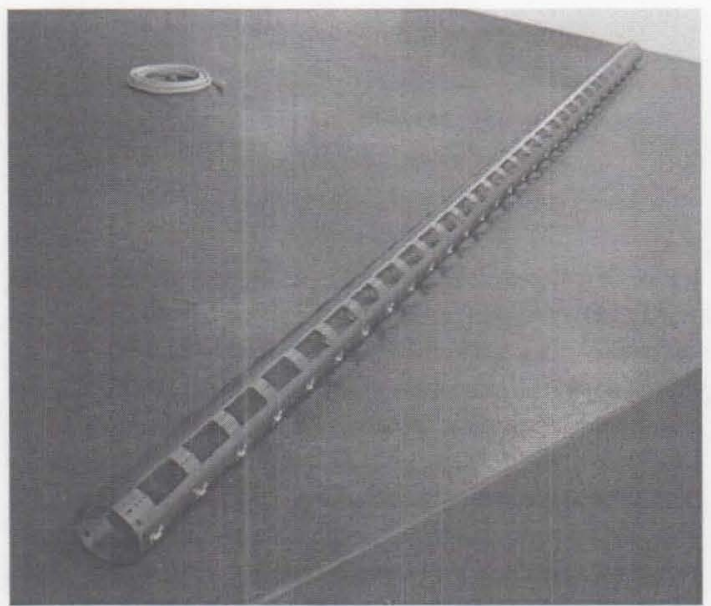

Figure 2. CRT 2.5i boom developed and built by ATK for the MRHE Phase 1 concept demonstration (length: $2.34 \mathrm{~m}$, diameter: $6.35 \mathrm{~cm}$, wall thickness: $0.33 \mathrm{~mm}$ ).

The goal of the CRT technology is to achieve a high-cycle deployable/retractable boom with a high Packing Factor $(<10)$ and superior stiffness/weight characteristics throughout its deployable range. CRT enables controllable deployment including precision retraction and repeatability. The materials that make up CRT are fully processed on ground and do not go through any chemical changes or thermal plastic deformation during or after deployment. Function and repeatability of flight hardware can be demonstrated prior to final packaging.

A partially deployed CRT boom is fully rigid and can resist loads in any direction. The design and configuration of the structural components provide an open center geometry enhancing the flexibility of the structure in terms of different uses and applications for which the structure is suitable. In certain applications, electronic components may be integrated with the structural components of the deployable structural assemblies. Additionally, CRT is readily scalable to any length or cross-sectional size, exhibits low thermal distortion properties, good damping characteristics and a low amount of stored energy when in a stowed state.

CRT is made up of two hingedly coupled composite shells that form a structurally efficient member capable of simple deployment from a rolled state and retraction back to a rolled state. The discrete flex joints, or FlexHinge ${ }^{\mathrm{TM}}$, couple the two free edges of composite shells to form a tubular structure. Both the composite shells and flex joints fold flat allowing CRT to be compressed flat. Once flattened, CRT can be rolled onto a spool. The offsetting or nested longeron design allows CRT to stow with minimal strain. The design of the deployable structural assemblies enables simplified manufacturing of the structural components and provides considerable flexibility in the manufacturing and design process of such structural components.

CRT is highly scalable in performance and length providing applicability to a wide range of applications. Performance is readily scaled by adjusting the material and sectional properties of the boom. Length is scaled by simply joining sections together. For instance, CRT can readily be scaled to $1 \mathrm{~m}$ in diameter and $100 \mathrm{~m}$ in length.

The following sections will provide an overview into the design of CRT as well as some basic performance metrics and analysis. There will be discussion of past CRT designs, namely CRT-2a/b and CTT, as well as the latest design CRT 2.5i which was built to fill the needs of the MRHE Phase 1 concept demonstration and not to characterize or push the limits of CRT technology. For example, MRHE Phase 1 Design Goal S2 (Bending Stiffness) was actually chosen to permit low-frequency $\left(1 \mathrm{~Hz} \leq \omega_{n} \leq 5 \mathrm{~Hz}\right)$ bending modes in the deployed configuration shown in Fig. 1. The intent was to set up a spacecraft attitude control problem involving flexible structural members. This problem was not explored in Phase 1 due to time and budget constraints.

\section{B. CRT Design}

CRT was developed to provide a good balance of simplicity and performance. It is similar to a simple inflatable boom in that it compresses flat and rolls onto a spool for storage. CRT, however, does not rely on inflation as a 
deployment mechanism. CRT utilizes fully processed high strength CFRP material as opposed to materials that are soft during deployment and rigidize once deployed, as is the case with rigidizable systems. Since CRT is made from fully processed materials, deployment and retraction are readily reversible and repeatable. This capability is made possible by specially engineered geometric configurations and materials that enable bending within the strain limits of the material allowing it to compact tightly without permanent damage.

CRT is made up of two CFRP shells consisting of longerons and battens (see Fig. 3, left). The shells are joined by an array of hinges, called FlexHinges ${ }^{\mathrm{TM}}$, which are spaced periodically along opposite sides of the boom. The flexibility of the battens and the FlexHinge ${ }^{\mathrm{TM}}$ allows the cross section of CRT to collapse and become flat. Once flat, the bending stiffness of the boom decreases dramatically, allowing it to roll up easily (see Fig. 3, right). Important considerations that affect the strain energy of the boom when rolled onto a spool include the diameter of the spool, diameter of the boom, shell material bending stiffness and geometric nesting of longerons. Too much strain energy and the boom could fail when being stowed. Too little strain energy indicates a conservative design. Generally speaking, higher performing CRT designs will maximize the strain energy available in the system. If the system has a low stored strain energy, it is implied that the boom could be rolled onto a smaller spool or more bending stiffness could be given to the shell material.
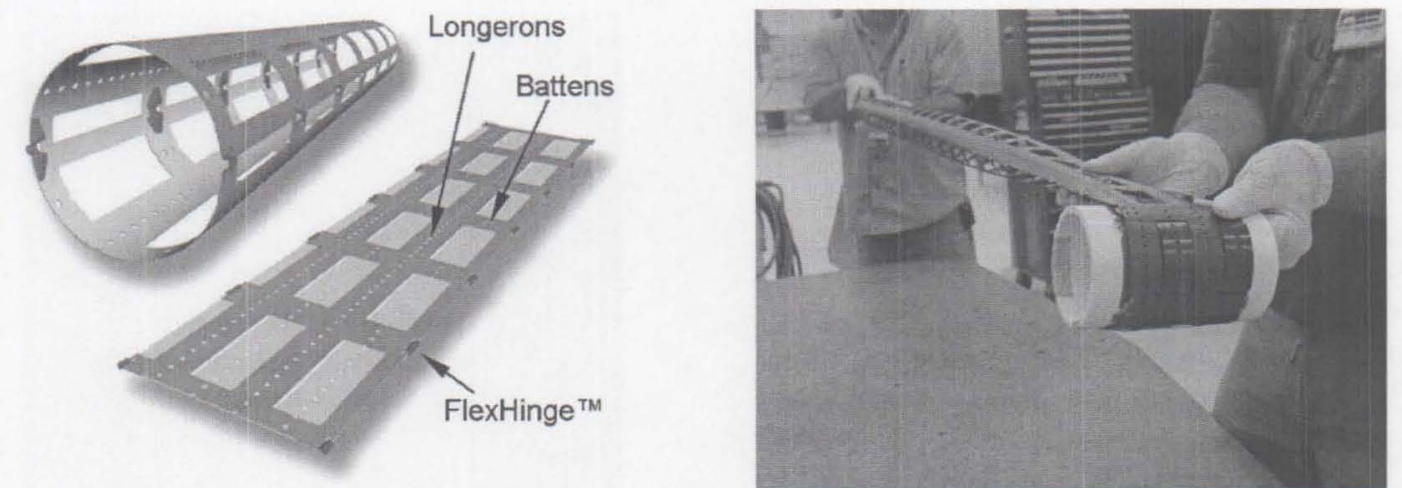

Figure 3. CRT Boom Elements. (left) CRT consists of two composite shells that are hingedly coupled with FlexHinges $^{\mathrm{TM}}$. (right) When CRT is compressed flat, the bending stiffness drops dramatically, allowing it to be rolled up.

\section{Shell Material}

The shells of the boom are generally made from high strength CFRP materials that are specially engineered for the desired in-plane and bending properties. Important in-plane properties include Young's modulus and CTE along the length of the boom. These properties dictate the bending, torsional and axial stiffness as well as the thermal stability of the boom. Important bending properties include bending about both the batten and longeron axis. These properties dictate the stored energy of the boom as well as the local stability of the longerons and cross section when deployed and under load. Both in-plane and bending properties are tailored by adjusting the CFRP ply constituents, orientation and stacking sequence.

Special hybrid lay-ups utilizing various fibers, at various angles and at various locations give the CRT shell superior flexibility in bending as well as good properties along the axis of the boom. It is a delicate balance between stowed and deployed performance requirements. CRT $2.5 \mathrm{i}$ presented a unique design challenge due to the small stowed volume and transition length requirements together with the relatively large deployed stiffness and strength requirements. Although the design of the shell laminate is only one component of the overall design, it is very critical and strongly dictates the overall success. The following are key material properties predicted using Classical Lamination Theory of the CRT $2.5 \mathrm{i}$ laminate material: thickness $=0.33 \mathrm{~mm}, \mathrm{E}_{\mathrm{x}}=75 \mathrm{GPa}, \mathrm{E}_{\mathrm{y}}=23 \mathrm{GPa}, \mathrm{Nu}_{\mathrm{xy}}=0.77$, $\mathrm{CTE}_{\mathrm{x}}=-0.9 \mathrm{ppm} /{ }^{\circ} \mathrm{C}, \mathrm{D}_{\mathrm{x}}=99 \mathrm{Nmm}, \mathrm{D}_{\mathrm{y}}=93 \mathrm{Nmm}$ and Density $=1.55 \mathrm{~g} / \mathrm{cm}^{3}(\mathrm{x}=$ axial direction $)$.

2. FlexHinges ${ }^{\mathrm{TM}}$

The two shells of the CRT boom are coupled together using hinge-like elements called FlexHinge ${ }^{\mathrm{TM}}$. FlexHinge ${ }^{\mathrm{TM}}$ is a strong, lightweight part that can fold flat by bending within the elastic region of the material (see Fig. 4). This is accomplished with either high strength titanium or CFRP materials. Key design elements include the thickness of the hinge material, the strength of the hinge material and the radii in which the bending must occur. The images in Fig. 4 show three distinct bending locations. It is possible that the middle be eliminated by taking the radii there to zero. This is nearly the case for CRT $2.5 \mathrm{i}$, where it was desirable to have the hinges stow as flat as 
possible. It was also desired that the hinge occupy a small volume with minimal protrusion beyond the edge of the boom. This defined the radii of the bending zones for the hinge which also loosely defined the thickness of titanium used.
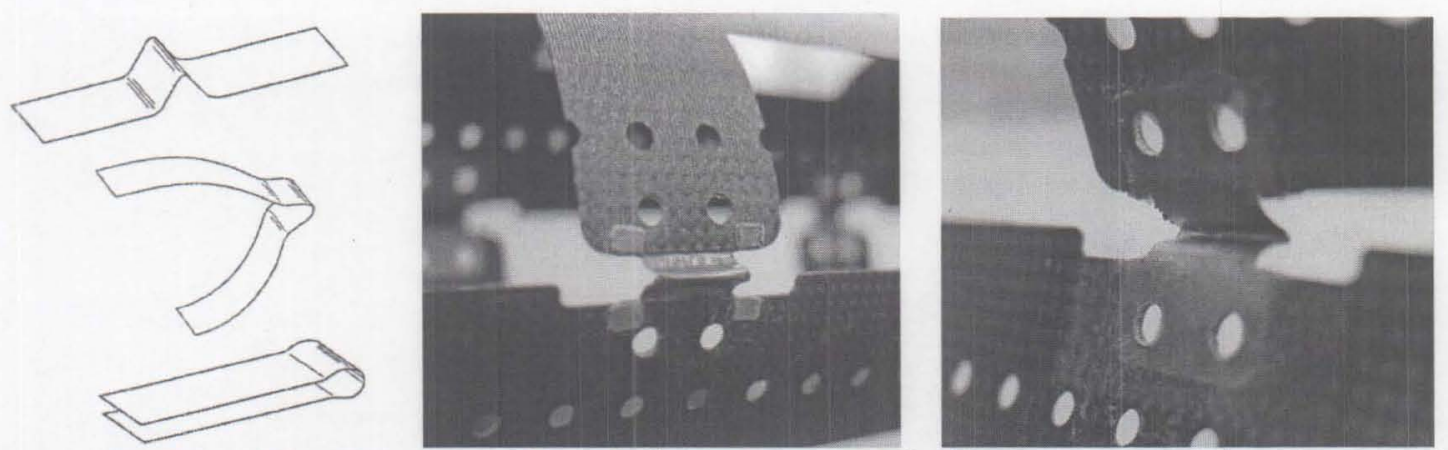

Figure 4. FlexHinges ${ }^{\mathrm{TM}}$. CRT consists of two shells hingedly coupled with FlexHinges ${ }^{\mathrm{TM}}$ that can bend and fold flat without yielding. CRT may be cycled between flat (stowed) and round (deployed) states hundreds of times without degradation.

The spacing of the FlexHinges ${ }^{\mathrm{TM}}$ depends on the shear load that they must transmit from one shell to the other. Spacing is also loosely dependent on the stability requirements of the longeron as the longerons become more stable with increasing batten rings (see Section III.E). The hinges are bonded to the shells using a structural adhesive. Tabs or rivets can be used to more securely attach the hinge to the shells to prevent peel failures. Special tools are used to precisely locate the hinge relative to the shells. Any misalignment between the shells will prevent the boom from collapsing correctly.

The compact and discrete design of the hinge is an important advantage over previous lenticular designs in which the bonded flanges add significantly to the stowed width of the boom. Whereas CRT's open architecture allows for easy detection and replacement of any damaged hinges, a continuous hinge is difficult to inspect and repair. Also, a continuous hinge implies that a continuous bond is made at the hinge location, which is not favorable in terms of thermal stability.

\section{Nested Longerons}

The longeron design is a key element to the performance and durability of CRT. Notice in Fig. 5 that the longerons do not overlap the longerons of the opposite shell when CRT is compressed flat. This allows the longerons associated with the inside shell to buckle through cut outs of the outside shell to relieve strain as the boom is rolled onto the spool. This may be illustrated with a deck of cards. It is easy to bend a deck of cards because each card bends about its own central (or neutral) axis. If the cards were glued together, you wouldn't be able to bend the deck because all of the cards would share a common neutral axis, resulting in a bending stiffness that is roughly $2,700 \mathrm{x}$ that of a non-bonded deck. The same thing happens with the longerons for CRT. Each longeron bends about its own neutral axis making the collapsed boom easy to roll. This strain relieving mechanism reduces the load on the hinges and in the shells dramatically. It also allows for thicker/stiffer shell laminate to be used which increases deployed performance. The nested longeron design is an obvious advantage over conventional non-nested lenticular designs.
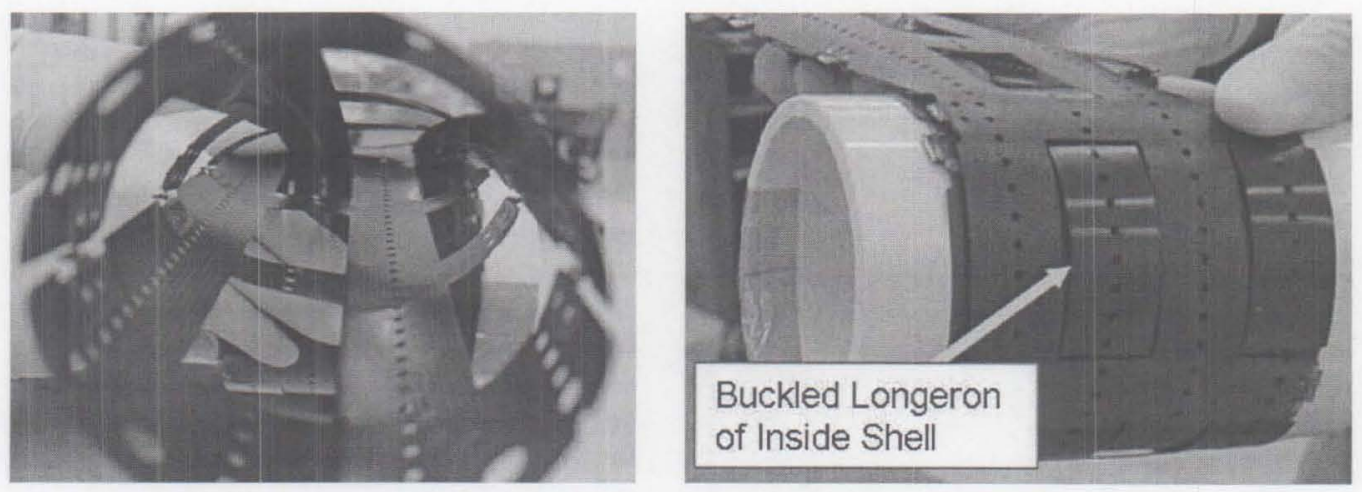

6

American Institute of Aeronautics and Astronautics 
Figure 5. Nested Longerons. Longerons of the opposing shells are designed to nest or not overlap, resulting in a significant reduction in stress on the shell and hinges when stowed.

\section{Indexing Drive}

In most applications, accurate and rigid deployment are desired features of a deployable boom system. Indexing Drive is an optional feature capable of providing just that. Indexing Drive is similar to how paper was fed in older dot matrix style printers. Two drive wheels with spiked teeth engage two columns of holes located along opposite edges of the paper to ensure accurate position and orientation. Indexing Drive for CRT is similar, except the holes are precision machined into the shells of the boom (see Fig. 6). The Indexing Drive Wheel has matching protrusions that engage the holes of the shell. At any given moment, at least two pins are engaged, eliminating slip and providing a rigid pin-like constraint. This is accomplished by clocking neighboring drive wheels so that penetrations of the pin in the hole are out of phase. Indexing Drive allows for precise knowledge of the boom position and provides a rigid constraint through which loads acting on the boom may be transmitted to the deployment mechanism.

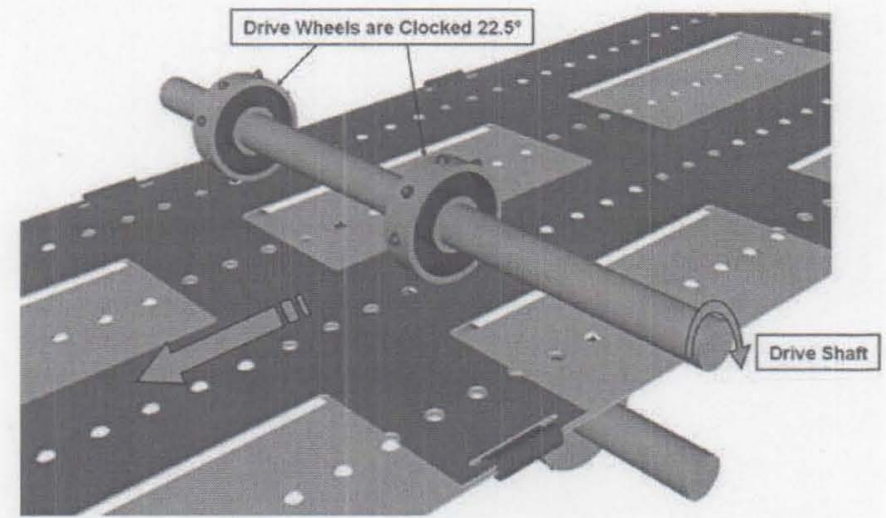

Figure 6. Indexing Drive. In order to provide accurate and rigid deployment of the CRT boom, the deployment mechanism uses Indexing Drive Wheels that engage precision machined holes in the shell.

\section{Mass Summary}

Mass per unit length is often a critical metric for very long deployable booms. CRT $2.5 \mathrm{i}$ has a mass per unit length of $64 \mathrm{~g} / \mathrm{m}$. The distribution of mass is summarized in Fig. 7, which shows that the longerons make up roughly $3 / 4$ of the total mass of the boom. It is important that the longerons account for as much of the boom mass as possible, for they dictate the overall deployed performance (e.g., bending stiffness) of the boom. Mass was not a critical driver in the CRT $2.5 \mathrm{i}$ design and was, therefore, not optimized. More mass could easily be taken out of the battens if necessary. Saving a few grams per meter is only really important when the boom is very long such as $100 \mathrm{~m}$ or greater. Otherwise, it is not worth cutting away more material or reducing the thickness, which could adversely impact the strength and stiffness of the boom.

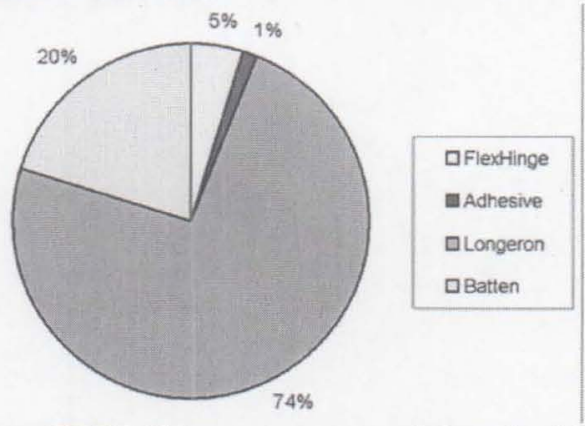

Figure 7. CRT Mass Summary. CRT $2.5 \mathrm{i}$ has a mass per unit length of $64 \mathrm{~g} / \mathrm{m}$ of which $74 \%$ represents longeron structure.

\section{Packing Efficiency}


The Packing Factor (PF) of a particular deployable structure may be calculated to describe its relative packing efficiency compared to other deployables. Packing Factor is defined as the total stowed volume of boom $\mathrm{V}_{\mathrm{s}}$ (including unusable space) divided by the boom material volume $V_{m}$ (the boom's mass divided by the material's density). Therefore, booms that are solid and contain no open geometry will tend to have a better PF when compared to the exact same boom that has cut outs. This is somewhat counter intuitive or confusing at first. Packing Factor simply describes at how well the material that makes up the boom is packaged. If there are holes in the package, then $\mathrm{PF}$ increases. Generally speaking, $\mathrm{PF} \leq 10$ is good. This means that the total stowed volume $\mathrm{V}_{\mathrm{s}}$ is only 10 (or less) times greater than the volume of material $\mathrm{V}_{\mathrm{m}}$ that makes up the boom.
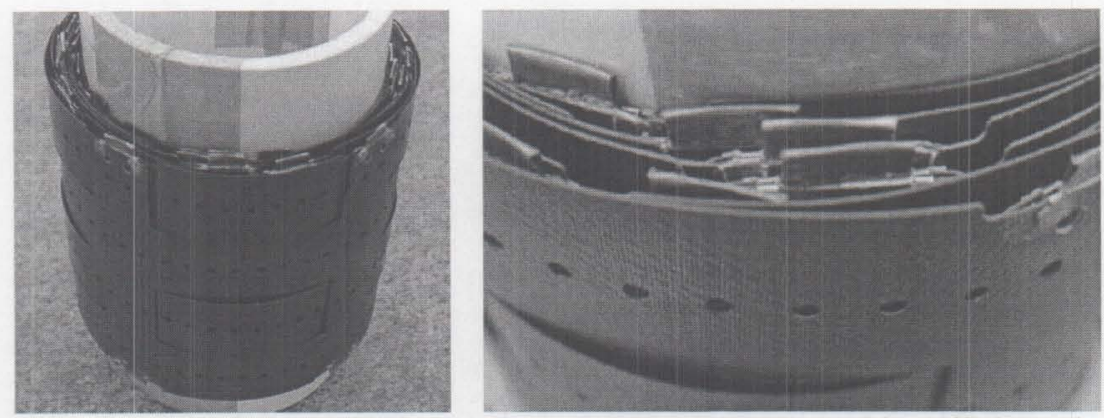

Figure 8. CRT 2.5i Stowed Boom on $8.9 \mathrm{~cm}$ diameter Spool. CRT's packing efficiency is very good and comparable to that of an inflatable.

CRT's packing efficiency is similar to that of an inflatable boom. Compressing flat and rolling is a very storage efficient configuration (see Fig. 8). However, CRT has an open architecture with a low $\mathrm{V}_{\mathrm{m}}$ which negatively impacts its Packing Factor. In Fig. 9 (left), the Packing Factor of CRT is plotted as a function of boom length. For a $20 \mathrm{~m}$ long boom, PF is about 4 and the spool diameter (including the thickness of the spooled boom) is about $20 \mathrm{~cm}$. The calculation of $\mathrm{V}_{\mathrm{s}}$ includes $670 \mathrm{~cm}^{3}$ for the inner core of unusable space inside the spool. It does not, however, account for the volumes of the deployment mechanism or the boom transition zone, both of which are required to fully characterize the system's total packing efficiency.
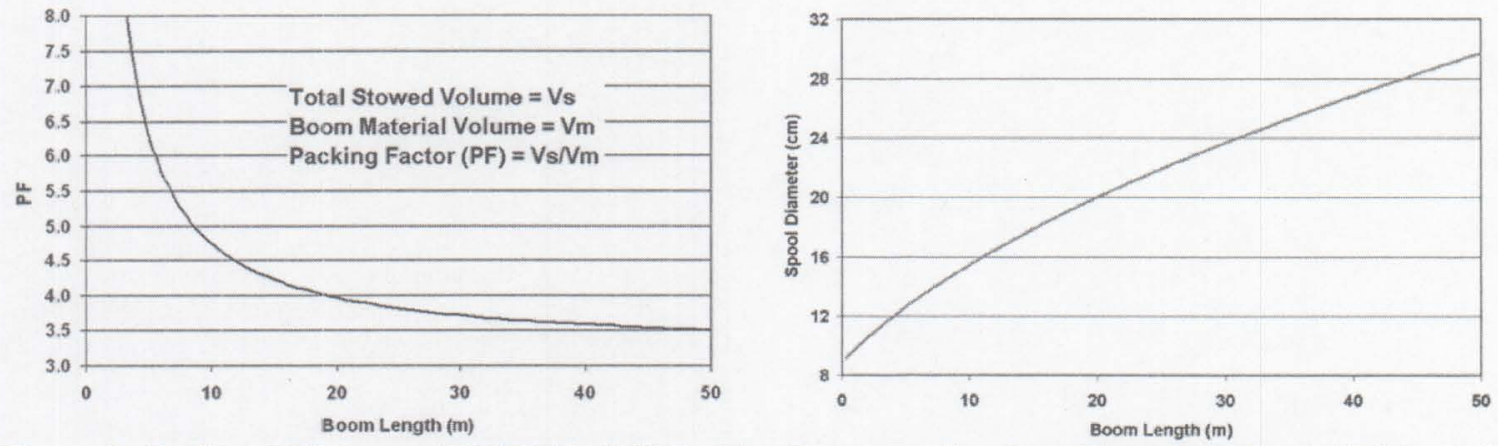

Figure 9. Packing Efficiency of CRT2.5i: (left) Packing Factor as a function of boom length and (right) spool diameter (including thickness of spooled boom) as a function of boom length.

\section{E. Finite Element Analysis}

Finite Element Analysis was conducted on CRT 2.5i to validate the boom's deployed performance prior to manufacture. The CRT 2.5i FEM shown in Fig. 10 was $2.06 \mathrm{~m}$ long and consisted of 20,000 linear thin shell elements. For purposes of the analysis, the base of the boom was rigidly constrained and a $0.69 \mathrm{~kg}$ mass was placed at the tip. The boom was evaluated for static deflection in a cantilevered orientation, linear buckling response and modes of excitation. 

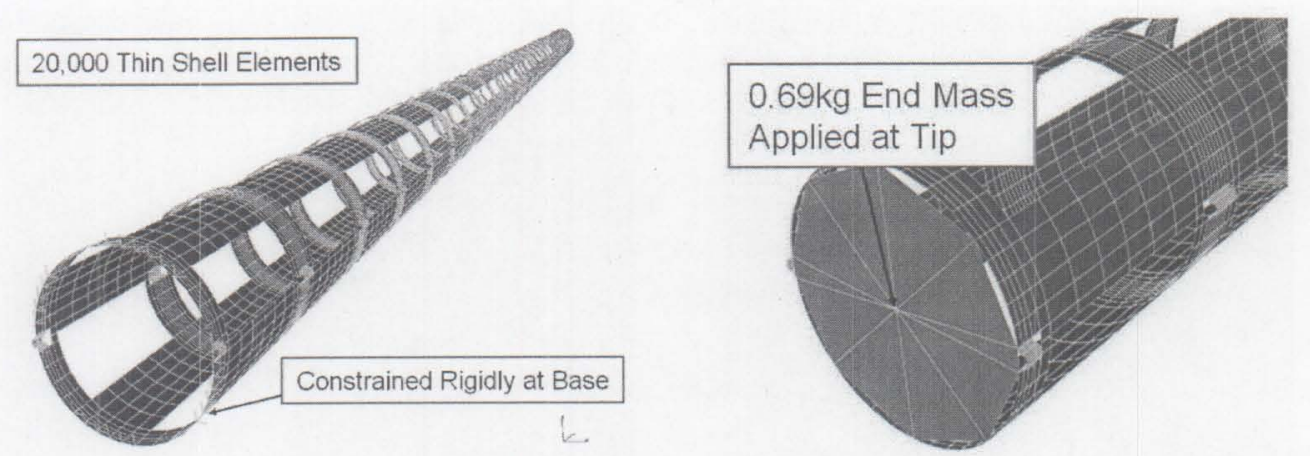

Figure 10. CRT 2.5i FEM. Finite Element Analysis was conducted to verify the deployed performance.

The deflection of CRT $2.5 \mathrm{i}$ with a cantilevered tip mass and $1 \mathrm{~g}$ of acceleration acting on it was $4.0 \mathrm{~cm}$ (see Fig. 11 , left). The average Von Mises stress in the longerons was approximately $7 \mathrm{ksi}$ which is roughly $1 / 10^{\text {th }}$ the compressive strength of the shell material. It is therefore assumed that the boom will not fail due to compressive skin failure. The Buckling Load Factor (BLF) is the factor of load that is required to initiate buckling. For this case, BLF is equal to 1.11. It is evident in Fig. 11 (right) that the longeron becomes unstable at this BLF or 1.11g. The mode is simply a sine wave-like deformation with the battens constraining out-of-plane deflection at each $180^{\circ}$ of phase. This was alluded to previously in Section III.B.2 in the discussion of spacing of hinges and how it loosely dictates the stability of the longeron. These results suggest that CRT $2.5 \mathrm{i}$ can support $0.69 \mathrm{~kg}$ in a cantilevered condition against $1 \mathrm{~g}$ without failure; however, any deviation or imperfection in the laminate or base support would likely reduce the BLF. The first four modes of excitation were bending at $2.44 \mathrm{~Hz}$, bending at $3.24 \mathrm{~Hz}$, twisting at $26.9 \mathrm{~Hz}$ and bending at $28.3 \mathrm{~Hz}$. These results suggest a minimum bending stiffness of roughly $560 \mathrm{Nm}^{2}$.

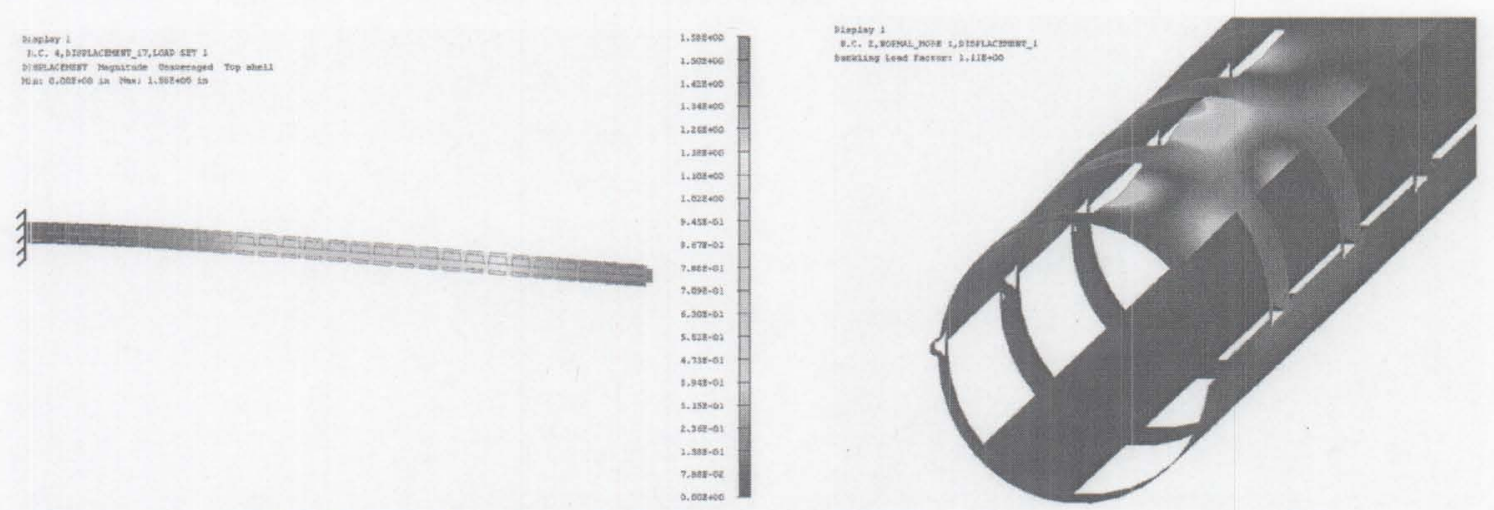

Figure 11. CRT 2.5i FEA Results. (left) Deformation of CRT 2.5i in the cantilevered condition with $1 \mathrm{~g}$ acting on it and (right) the $1^{\text {st }}$ buckling mode in the same cantilevered condition.

\section{F. Alternate CRT Design}

There have been a few different forms of CRT prior to 2.5i. Most notable among these was CRT 2, designed for Lockheed Martin by ATK for the ST- 8 Study Phase. CRT 2 was really the first of its kind and the nomenclature bears no real significance. CRT 2 was $12.7 \mathrm{~cm}$ in diameter and consisted of eight longerons held together with a lattice-like web (see Fig. 12). The web provided diagonal supports for the longerons but was later hypothesized as unnecessary; hence, the adoption of simple batten rings for CRT 2.5i. The linear density of CRT 2 was $65 \mathrm{~g} / \mathrm{m}$ and the deployed boom had a bending stiffness of roughly $4000 \mathrm{Nm}^{2}$. CRT 2 and $2.5 \mathrm{i}$ worked in much the same way. They both utilized FlexHinges ${ }^{\mathrm{TM}}$ and both had nesting longeron designs. CRT 2, however, did not have indexing features. 

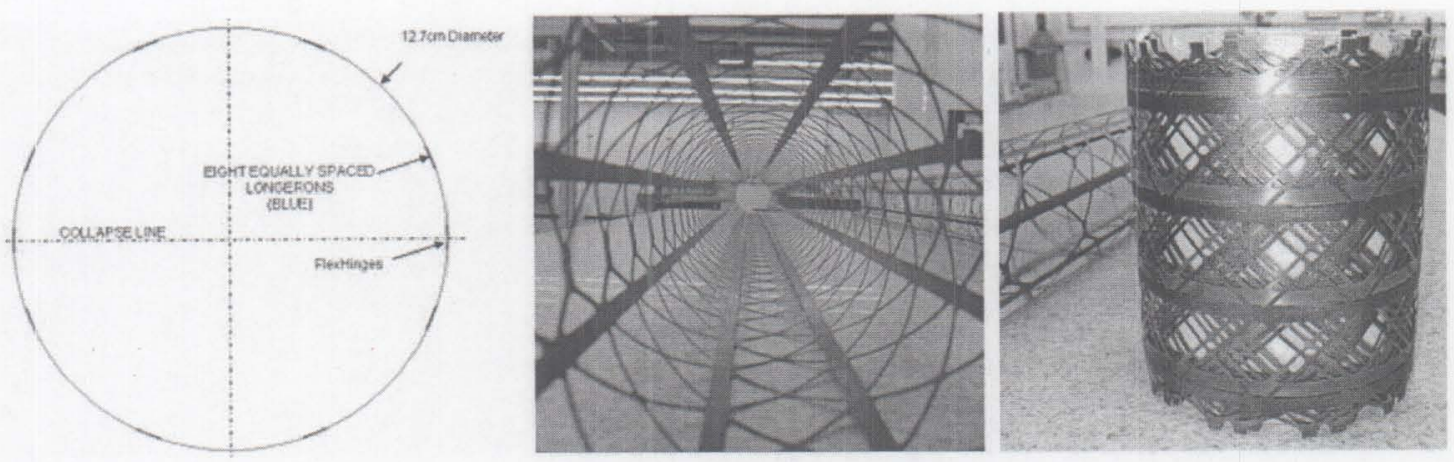

Figure 12. CRT 2a/b. (left) The cross section of CRT 2a/b, (middle) CRT $2 b$ deployed and (right) CRT $2 b$ stowed onto a spool.

\section{G. Advantages of CRT Technology}

CRT technology addresses several shortcomings of other spooling boom systems. Inflatable booms, for one, require inflation followed by a chemical reaction or phase change to rigidize the boom. CRT utilizes fully processed materials, allowing the boom to be repeatably deployed and retracted. The ability to deploy the flight boom several times prior to launch reduces risk. CRT also allows for a high degree of deployment control. This is possible due to the rigid state of the boom upon exiting the deployment mechanism, making it possible to point the boom or change its heading during any phase of deployment.

The open architecture of CRT provides important advantages over closed profile designs such as the lenticular Collapsible Tube Technology (CTT) boom manufactured for Lockheed Martin by ATK as part of the ST-8 Study Phase effort (see Fig. 13). CTT works in the same way as most inflatable boom technologies and CRT. To stow the boom, the cross section is compressed flat and the boom is rolled onto the spool.

The basic form of CTT is a fully closed boom architecture that is difficult to manufacture and repair. CTT incorporates a continuous hinge design that runs the entire length of the boom, resulting in poor thermal stability and a common point of failure when rolled. The shells of CTT lie flat on top of one another, resulting in high bending stiffness when the boom is collapsed and, thus, high stresses in the shells and bond joints when the flattened boom is rolled.
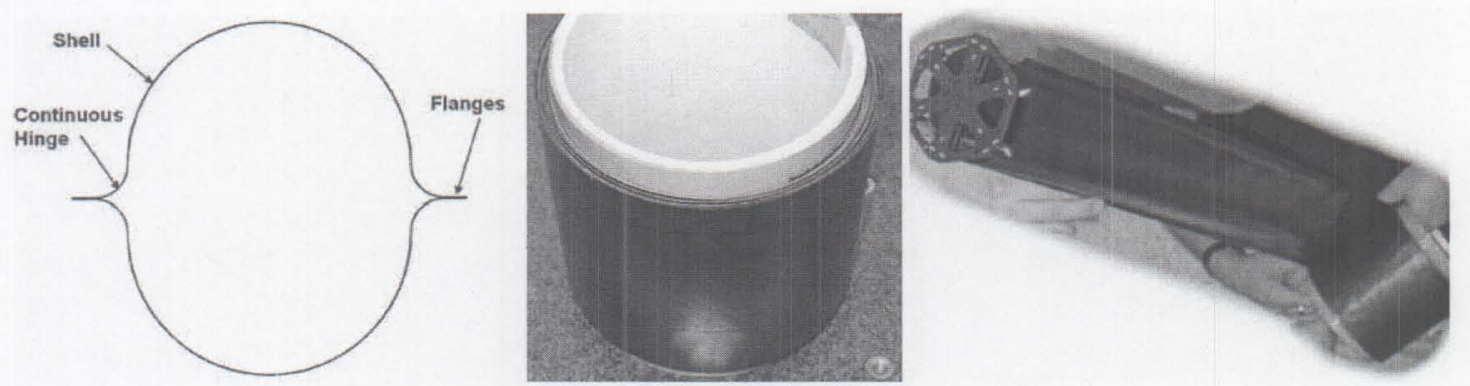

Figure 13. Lenticular Collapsible Tube Technology (CTT). The boom shown here was manufactured for Lockheed Martin as part of the ST-8 Study Phase effort. The new CRT design addresses many of the shortcomings of lenticular boom technology.

The primary differences between CRT and CTT involve the open architecture, FlexHinge ${ }^{\mathrm{TM}}$ and nested longeron design. From a thermal stability standpoint, the lattice type design reduces thermal gradients from one side of the boom to the other, minimizing thermally-induced bending. In addition, the open lattice facilitates manufacturing, inspection and repairs because interior surfaces can be visually inspected and readily accessed. The advantages of FlexHinges ${ }^{\mathrm{TM}}$ and nested longerons were described, respectively, in Sections III.B.2 and III.B.3. 


\section{Boom Deployment Mechanism}

\section{A. Technical Summary}

The Boom Deployment Mechanism (BDM) features a spring-loaded positive engagement drive, encoder-based position control, and end-of-travel/homing switches. Figure 14 shows the CRT boom (partially deployed, with a docking probe attached) and the BDM. The positive engagement drive helps to ensure that the boom stays centered on the rollers and does not walk off to one side or the other. It achieves this with toothed rollers that engage rows of drive holes along the boom longerons, similar to older computer printer paper feed mechanisms. Because the boom cannot slip when between the rollers, the deployed length can be accurately measured from deployment motor encoder counts.

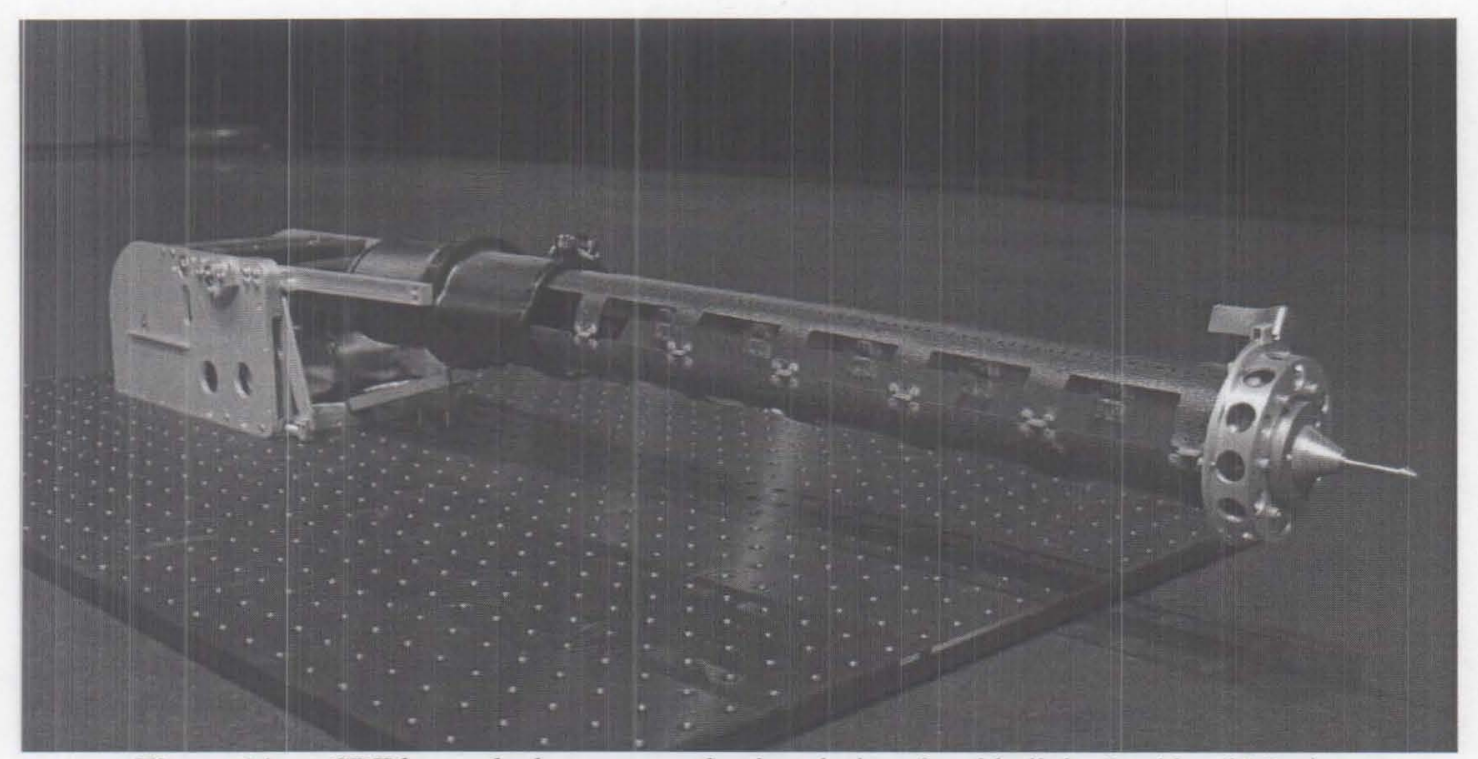

Figure 14. CRT boom deployment mechanism designed and built by Lockheed Martin.

\section{B. Overview}

The BDM includes three main functional subassemblies in direct contact with the boom, each of which will be discussed in detail. They include the storage spool subassembly, the drive roller subassembly, and the support collar subassembly. A CAD model of the mechanism is shown in Fig. 15 with covers and sidewall removed for clarity. 


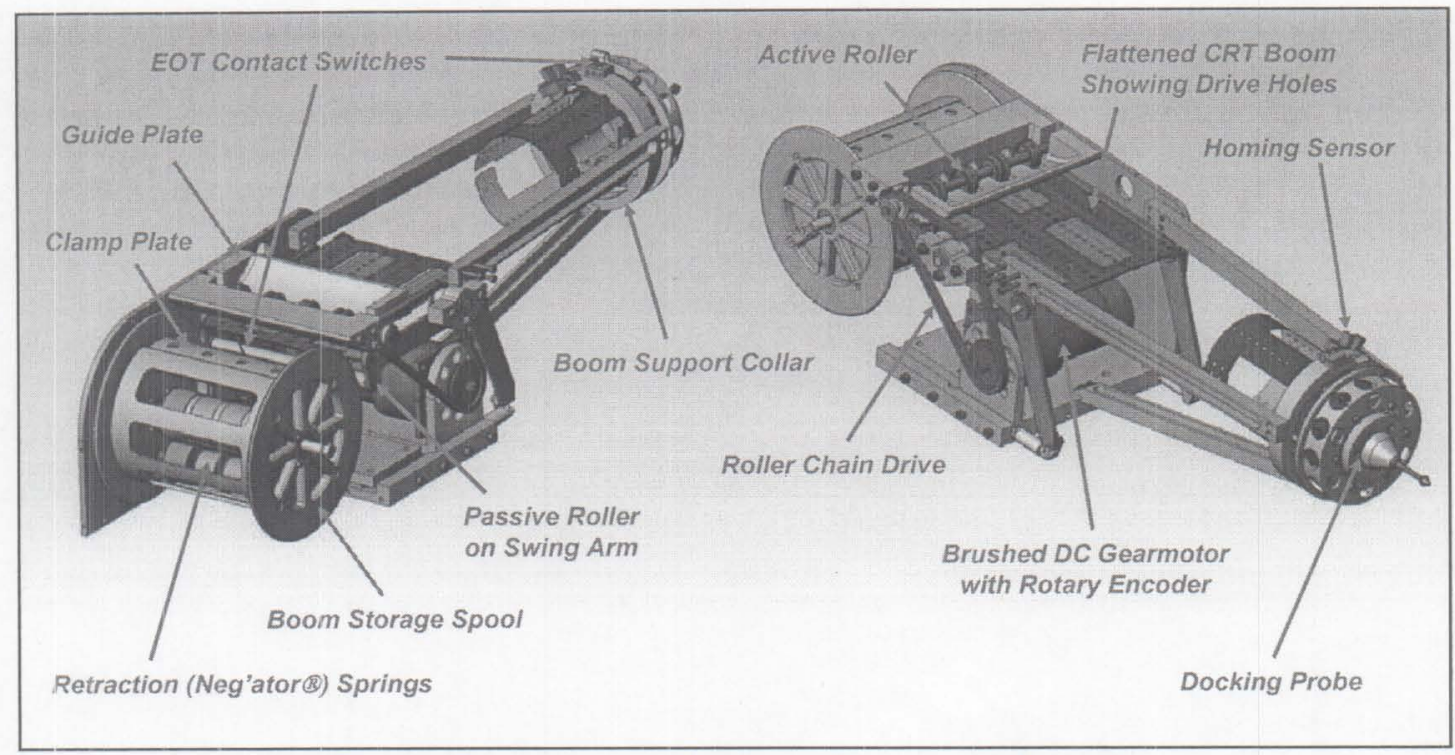

Figure 15. Anatomy of the Boom Deployment Mechanism.

\section{The Storage Spool Subassembly}

The storage spool subassembly consists of a $9 \mathrm{~cm}$ diameter aluminum spool, its support bearings and the boom retraction springs housed inside of it. The CRT boom is installed by means of a clamp plate that flattens the boom against the spool surface. Matching clearance holes are provided in the top and bottom halves of the boom for this purpose.

The spool is supported by roller bearings mounted on a central shaft fixed to the BDM housing. Internal to the spool is a boom retraction spring subassembly consisting of four Neg'ator ${ }^{\circledR}$ springs arranged in a parallel drum configuration. Neg'ator ${ }^{\circledR}$ springs consist of long strips of 301 stainless steel wound tightly around a mandrel during fabrication and heat-treated to deliberately induce residual stresses. An unconstrained Neg'ator ${ }^{\circledR}$ spring will coil up on itself in a tight spiral with adjacent turns in contact. When the spring is uncoiled by flattening it or reversing its curvature, energy is stored at a nearly constant rate. This energy may later be used to do useful work, as in the spring motor used to retract a common tape measure.

By providing a restoring torque that remains nearly constant as the spool rotates, the boom retraction spring subassembly keeps the flattened boom material between the storage spool and drive rollers in tension. As the boom is deployed and retracted, this tension must be maintained to ensure that the boom winds tightly around the storage spool. A loosely wound boom could contact the cover of the BDM as it rotates, resulting in scuffing of the boom surface or jamming of the mechanism.

In the boom retraction spring subassembly, a single Neg'ator ${ }^{\circledR}$ spring output drum is fixed to the central spool support shaft. Individual spring storage drums are free to spin about a parallel shaft fixed to the spool sidewalls. As the drive rollers deploy the boom, spring material is unrolled from the spring storage drums and rolled onto the spring output drum while reversing curvature. When the boom drive rollers reverse direction, spring material is returned to the spring storage drums. This parallel drum configuration operates with a nearly flat torque profile and stores energy at a nearly constant rate.

2. The Drive Roller Subassembly

The drive roller subassembly includes the active and passive rollers, the passive roller swing arm, and the drive motor. By means of Electrical Discharge Machining (EDM), each roller is cut from a single bar of 303 stainless steel with two rows of drive teeth and two grooved wheels. Each row of drive teeth mates with a groove on the opposing roller when the BDM is assembled. Positive engagement is achieved when the drive teeth penetrate the rows of matching drive holes found on both the top and bottom halves of the collapsed boom.

A brushed DC gearmotor drives the active roller by means of a roller chain tensioned with an adjustable idler. The motor gearhead reduction ratio is chosen so that the drivetrain is non-backdriveable, allowing the drive roller subassembly to react the tension developed in the boom by the retraction springs even when power is removed from the motor. The passive roller spins freely and travels on a spring-loaded swing arm to maintain compression on the 
boom, ensuring it remains sandwiched flat between the rollers for maximum drive tooth penetration. A guide plate protects boom life by ensuring that the boom does not violate its minimum bend radius while flattened.

Positive engagement of the flattened boom allows the boom to be metered off the storage spool without slippage. Thus, an encoder mounted to the motor shaft can be used to accurately measure the length of the deployed section. In addition, lateral stability of the boom is enhanced because the boom is continuously pinned in place between the drive rollers. During retraction, there is no possibility of the boom riding up on the edges of the storage spool due to poor tracking.

3. The Support Collar Subassembly

The support collar subassembly reacts lateral loads applied at the tip of the boom. It provides a second boundary condition for the transition region in which the boom develops from a flat cross-section to a round cross-section. The first boundary condition is provided by the pinching action of the drive rollers. The shape of the boom in the transition region is the natural result of strain energy distribution in the boom structure. While it is desirable to reduce the length of the transition region as much as possible, there are practical limits beyond which the boom will buckle inward to relieve localized strain energy. This was observed to be especially stressing for the titanium hinges near the buckling section of boom with at least one recorded failure. No failures of the composite laminate were observed.

Strictly speaking, the full strength and stiffness of the boom are not developed until the clamped end condition used in the Finite Element Analysis of Section III.E is enforced. A support collar capable of uniformly clamping around any arbitrary segment of the boom profile was beyond the scope of the Phase 1 concept demonstration.

\section{Design Calculations}

The feasibility of using a spring mechanism instead of a second motor to wind the boom onto the spool during retraction was evaluated by estimating the strain energy stored in the collapsed boom on the spool vs. the energy stored in the Neg'ator ${ }^{\circledR}$ springs located inside the spool. As the boom is deployed, energy is released by the boom and stored by the springs at a nearly constant rate with respect to deployed length $(\mathrm{J} / \mathrm{m})$. If the net energy of the system increases as the boom deploys, the drive motor does work in extending the boom. This is equivalent to keeping the flattened boom in tension between the spool and drive rollers. Conversely, during boom retraction, the system does work on the motor, which then acts as a brake preventing the boom from returning to the spool all at once. The challenge was to design a spring mechanism compact enough to fit inside the spool but with sufficient torque to keep the boom tightly wound around the spool.

1. Strain energy in the boom

The deploying boom geometry is shown in Fig. 16.

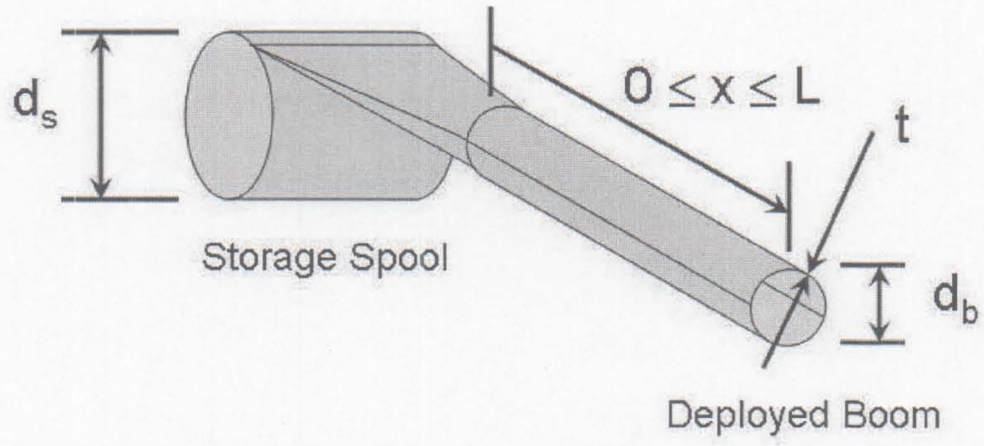

Figure 16. Critical dimensions in the geometry of the deploying boom.

The total strain energy stored in an elastic shell is given by:

$$
U=U_{b}+U_{s}
$$

where $U_{b}$ is the bending strain energy and $U_{s}$ is the stretching strain energy. ${ }^{10}$ Iqbal and Pellegrino have developed expressions for computing these strain energies in composite slit tubes. ${ }^{7}$ Because the BDM and CRT were 
developed concurrently, inputs to Eq. (1) were not available to help size the retraction springs. Moreover, a theoretical method would give only approximate results because it would be difficult to account for the effects of the FlexHinge $^{\mathrm{TM}}$ joints and aggressive lightweighting of the laminate discussed, respectively, in Sections III.B.2 and III.B.3.

To get a rough order of magnitude estimate of strain energy before the CRT $2.5 \mathrm{i}$ design was complete, the top and bottom half-cylinders of the boom were modeled as separate, thin-walled elastic shells with isotropic material properties. The elastic energy stored in collapsing and spooling such a structure depends on whether it is forwardwound or backward-wound ${ }^{11}$ and is given by:

forward wound:

$$
\begin{aligned}
& V_{f w d}=\frac{E}{1-v^{2}} \frac{\gamma \pi t^{3}(l-x)}{6 d_{0}}\left(1+\frac{d_{0}^{2}}{D^{2}}-\frac{2 v d_{0}}{D}\right) \\
& V_{b w d}=\frac{E}{1-v^{2}} \frac{\gamma \pi t^{3}(l-x)}{6 d_{0}}\left(1+\frac{d_{0}^{2}}{D^{2}}+\frac{2 v d_{0}}{D}\right)
\end{aligned}
$$

In the above equations, the strain energy computation considers only elastic bending in the shells because the boom is flattened before it is spooled. The resulting profile has a negligible cross-section moment of inertia when wrapped around the spool so that $U_{s} \approx 0$. Adopting the present nomenclature:

forward wound:

$$
V_{f w d}=\frac{D \pi(L-x)}{d_{b}}\left(1+\frac{d_{b}^{2}}{d_{s}^{2}}-\frac{2 v d_{b}}{d_{s}}\right)
$$

backward wound:

$$
V_{b w d}=\frac{D \pi(L-x)}{d_{b}}\left(1+\frac{d_{b}^{2}}{d_{s}^{2}}+\frac{2 v d_{b}}{d_{s}}\right)
$$

where $D$ is the flexural rigidity of the shell from elastic plate theory.

$$
D=\frac{E t^{3}}{12\left(1-v^{2}\right)}
$$

By symmetry, the top and bottom halves of the boom are assumed to be decoupled during flattening with the hinges along the edges acting as single-DOF pinned joints. During spooling, these hinges prevent shearing between the flattened shells, which would ordinarily increase spooling stiffness. However, as discussed in Section III.B.3, the novel nested-longeron design of CRT is intended to decouple bending of the two shells as much as possible during spooling. In consideration of these features, the total strain energy stored in the spooled boom is estimated as the sum of the energy in the top half (forward wound) and the bottom half (backward wound), taken separately:

$$
U_{b o o m} \approx V_{f w d}+V_{b w d}=\frac{2 D \pi(L-x)}{d_{b}}\left(1+\frac{d_{b}^{2}}{d_{s}^{2}}\right)
$$

The mechanical properties of a hypothetical boom are summarized in Table 2. The flexural rigidity of the hypothetical boom material roughly approximates the predicted flexural rigidity of the CRT laminate presented in Section III.B.1. Because $D$ is the only material property appearing in Eq. (7), representative strain energy calculations may be made despite the fact that $E$ and $v$ are quite different for the two materials. In Eq. (7), the terms in the second set of parentheses can be considered, respectively, scaling factors for the collapsing energy and spooling energy. Due to the geometry of the deploying boom, the ratio is $2: 1$. 
Table 2. Mechanical properties of a hypothetical deploying boom.

\begin{tabular}{|l|c|c|}
\hline & Units & Value \\
\hline Thickness, Laminate, $\mathbf{t}$ & $\mathrm{mm}$ & 0.33 \\
\hline Diameter, Deployed Boom, $\mathbf{d}_{\mathbf{b}}$ & $\mathrm{cm}$ & 6.35 \\
\hline Diameter, Boom Storage Spool, d $\mathbf{s}_{\mathbf{s}}$ & $\mathrm{cm}$ & 9.00 \\
\hline Total Deployable Length, L & $\mathrm{m}$ & 2.00 \\
\hline E & $\mathrm{GPa}$ & 34.5 \\
\hline $\boldsymbol{v}$ & & 0.3 \\
\hline Flexural Rigidity, Single Shell, D & $\mathrm{N}-\mathrm{mm}$ & 114 \\
\hline Stiffness, Single Shell Collapsing, E'I & $\mathrm{N}-\mathrm{m}^{2}$ & .227 \\
\hline Strain Energy, Double Shell Collapsing (per unit length boom spooled) & $\mathrm{J} / \mathrm{m}$ & 11.2 \\
\hline Stiffness, Single Shell Spooling, E'I & $\mathrm{N}-\mathrm{m}^{2}$ & .0113 \\
\hline Strain Energy, Double Shell Spooling (per unit length boom spooled) & $\mathrm{J} / \mathrm{m}$ & 5.59 \\
\hline Strain Energy, Total, $\mathbf{U}_{\text {boom }}$ (per unit length boom spooled) & $\mathrm{J} / \mathrm{m}$ & 16.8 \\
\hline
\end{tabular}

2. Strain energy in the springs

The retraction spring mechanism geometry is shown in Fig. 17.

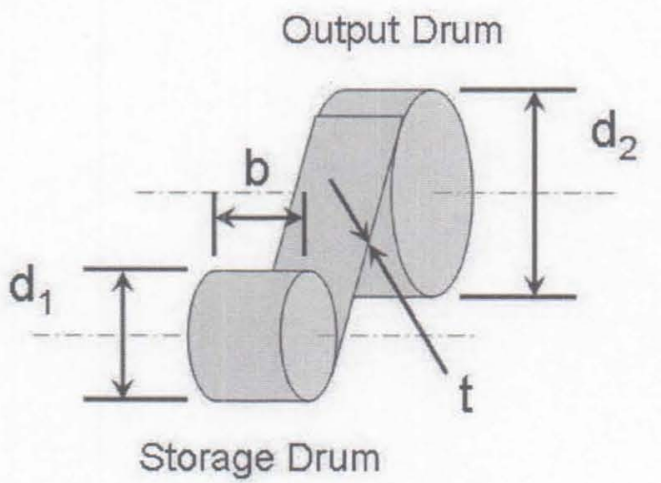

Figure 17. Critical dimensions in the geometry of the constant torque (parallel drum) spring motor.

In reality, the Neg'ator ${ }^{\circledR}$ spring behaves much more like a wide rectangular beam in elastic bending than the flattened CRT boom does. Accordingly, a much more accurate estimate of the spring strain energy should be expected when the following equations are applied. The torque produced by the Neg'ator ${ }^{\circledR}$ springs in a constant torque (parallel drum) spring motor is approximated by Postma ${ }^{12}$ as:

$$
T=\frac{E W D_{2} t^{3}}{12\left(1-v^{2}\right)}\left(\frac{1}{D_{1}}+\frac{1}{D_{2}}\right)^{2}
$$

Adopting the present nomenclature:

$$
T_{r}=\frac{E b d_{2} t^{3}}{12\left(1-v^{2}\right)}\left(\frac{1}{d_{1}}+\frac{1}{d_{2}}\right)^{2}=D b d_{2}\left(\frac{1}{d_{1}}+\frac{1}{d_{2}}\right)^{2}
$$

Postma approximates the maximum stress in the spring material due to bending with:

$$
\sigma_{b}=E^{\prime} \varepsilon_{b}=\frac{E t}{\left(1-v^{2}\right)}\left(\frac{1}{d_{1}}+\frac{1}{d_{2}}\right)
$$


where $E^{\prime}$ is the factor conventionally used to adapt standard beam bending formulas to wide beams. ${ }^{13}$

$$
E^{\prime}=\frac{E}{\left(1-v^{2}\right)}
$$

From these equations, it can be seen that $T_{r}$ is directly proportional to the flexural rigidity $D$ and width $b$ of the spring material. Adding parallel sets of springs has the same effect as increasing the width of the individual springs. Increasing $D$ by thickening the spring increases the stress in the spring material and may adversely affect spring life. Drum diameter selection is limited by the boom storage spool inside diameter, which determines the packaging volume for the retraction spring mechanism.

Because the spring output drum is fixed to the spool central shaft, one full turn of the spool lays down one layer of spring material onto the output drum. The total strain energy stored in the spring is equal to the work done in winding the spring from the storage drum to the output drum and may be approximated as:

$$
U_{\text {spring }}=\int_{0}^{\theta_{f}} T_{r} d \theta=T_{r} \frac{2 x}{d_{s}}
$$

Three commercially available Type 301 Stainless Steel Neg'ator ${ }^{\circledR}$ springs with different stock thicknesses and widths were compared to determine if a retraction spring mechanism would be feasible. Up to four springs can be installed side-by-side in the retraction spring mechanism. The results, presented in Table 3 , eliminate springs B and $\mathrm{C}$ from consideration because of the high stresses developed. This was confirmed later in testing in which the springs yielded during the first boom deployment cycle. Spring A, on the other hand, has survived repeated cycles despite predicted stresses in excess of its tensile strength. Postma offers an explanation of this phenomenon. ${ }^{12}$

\begin{tabular}{|c|c|c|c|c|}
\hline & Units & Spring A & Spring B & Spring $\mathbf{C}$ \\
\hline Thickness, Spring Steel Strip, t & in & 0.006 & 0.008 & 0.010 \\
\hline Width, Spring Steel Strip, b & in & 0.375 & 0.5 & 0.625 \\
\hline E (Type 301 Stainless Steel) & $\mathrm{GPa}$ & \multicolumn{3}{|c|}{193} \\
\hline$v$ & & \multicolumn{3}{|c|}{0.3} \\
\hline Flexural Rigidity, D & $\mathrm{N}-\mathrm{m}$ & .0626 & .148 & .289 \\
\hline Number of Springs Installed & & 4 & 4 & 3 \\
\hline Diameter, Storage Drum, $d_{1}$ & $\mathrm{~cm}$ & \multicolumn{3}{|c|}{2.03} \\
\hline Diameter, Output Drum, $\mathbf{d}_{2}$ & $\mathrm{~cm}$ & \multicolumn{3}{|c|}{2.92} \\
\hline Torque, $T_{r}$ & $\mathrm{~N}-\mathrm{m}$ & 0.49 & 1.53 & 2.81 \\
\hline Maximum Stress, $\sigma_{\mathrm{b}}$ & $\mathrm{GPa}$ & 2.69 & 3.60 & 4.49 \\
\hline Strain Energy, $\mathbf{U}_{\text {spring }}$ (per unit length boom deployed) & $\mathrm{J} / \mathrm{m}$ & 10.8 & 34.1 & 62.4 \\
\hline
\end{tabular}

Table 3. Mechanical properties of the retraction spring mechanism.

3. Net strain energy

The net strain energy is the sum of the energy stored in the boom and the energy stored in the springs. Figure 18 shows a plot of the estimated strain energies versus deployed boom length. Because the drive motor does the work of collapsing the boom during retraction, only the boom spooling energy is considered in sizing the retraction springs. The results suggest that a parallel drum configuration using spring A could store enough energy to offset the energy released by the boom as it rolls off the spool. 


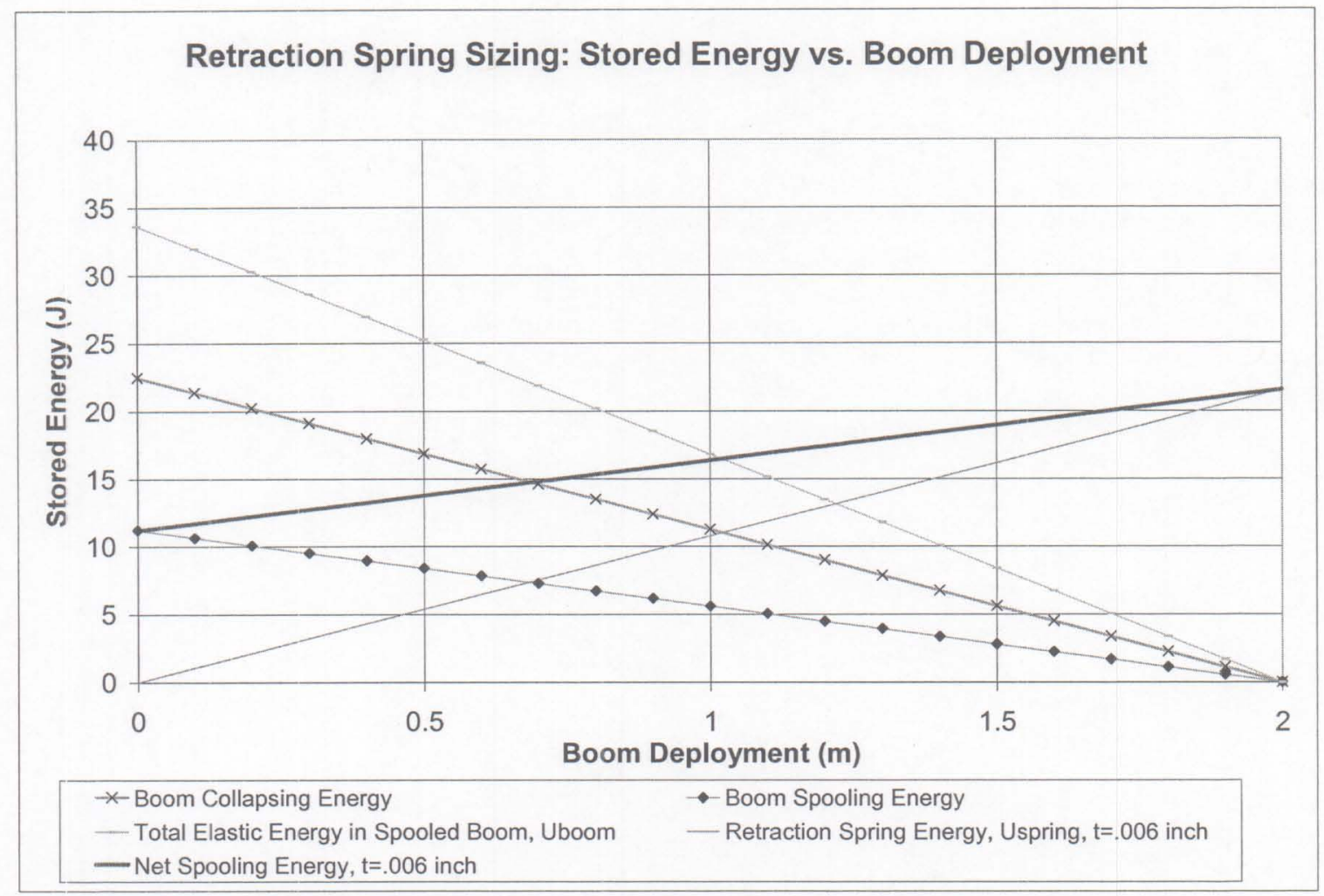

Figure 18. Strain energy calculation results for hypothetical boom.

The preliminary design calculations discussed herein did not entirely eliminate the risk involved in proceeding with a BDM design compatible only with the proposed retraction spring mechanism. For this reason, a motorized retraction option was built into the design in the event that testing of the spring mechanism should prove unsuccessful. Moreover, there are practical limitations to spring-loaded spooling as $L$ increases unless the empty volume inside the boom storage spool is increased accordingly to house longer Neg'ator ${ }^{\circledR}$ springs. Adding a second motor to power the boom storage spool was deemed a simpler solution than providing a reversing gearbox as in Ref. 8.

Conceptually, the controller for a dual motor BDM could be almost as simple as for a single motor BDM with spring return. To deploy the boom, the drive roller motor operates at constant torque (i.e., constant current), keeping the boom in tension while the storage spool motor meters out material off the spool. To retract the boom, the roles are reversed. Fortunately, the second motor was never needed because the retraction spring mechanism with four $0.006 "$ thick springs installed had sufficient torque to keep the boom tightly wound on the spool. For even more torque, $67 \%$ wider springs of the same thickness could have been used but procuring them would have required an expensive custom part order of 100 units.

\section{Boom Integration}

Because the MRHE concept demonstration was to be conducted on an air-bearing table (albeit a rather large one), a deployable boom length of 1.5 meters was considered sufficient for Phase 1 (see Fig. 19), though it fell short of design goal S3 $(L=2.0 \mathrm{~m})$. Initially, the boom support collar consisted of a circular ring with rounded lead-in surfaces on both internal edges contacting the boom and relief notches permitting passage of the titanium hinges. In early testing, it was found that this collar did not provide adequate support for the boom as the transition length (i.e., the distance between the drive rollers and the collar) was decreased because the contact region shrank from uniform surface contact to edge contact along two opposing longerons. Without the needed support, the boom did not transition as intended but, instead, assumed an elliptical shape at the collar until the transition length was increased to 8 times the boom diameter $\left(8 d_{b}\right)$. This longer transition length was achieved by lengthening the support arms attached to the collar. 


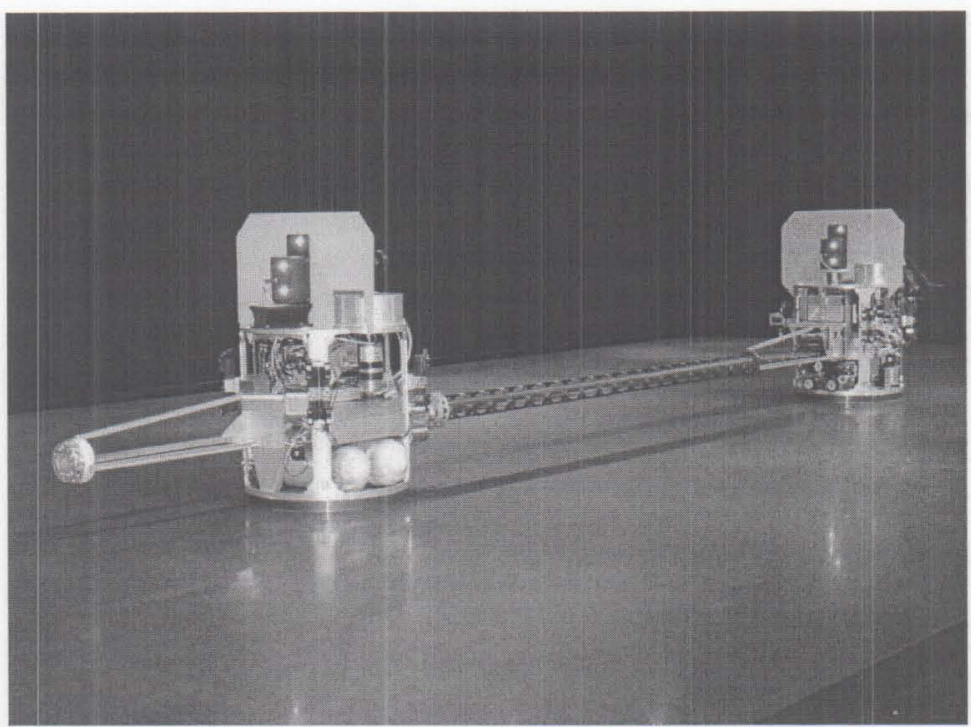

Figure 19. CRT boom connecting two robotic spacecraft and deployed to $1.5 \mathrm{~m}$.

A desire to increase $L$ by shortening the boom transition length led to the development of a new, specially formed collar (shown in Fig. 14) controlling the boom profile over a longer portion of the transition region than the original collar (shown in Fig. 19). The shortest transition length achieved for the $6.35 \mathrm{~cm}$ diameter CRT-2.5i boom during MRHE Phase 1 was $35.7 \mathrm{~cm}$, or a transition length of $5.6 d_{b}$. Installation of the new collar yielded 15 additional centimeters of deployable length in the same package, for a total deployable length of $1.65 \mathrm{~m}$.

Integration of the BDM onto the robotic spacecraft used in the MRHE Phase 1 concept demonstration went very smoothly and all objectives of the demonstration were met on schedule. The booms have been repeatedly cycled with no noticeable degradation over the course of numerous filming sessions and live demonstrations.

\section{Conclusion}

Overviews of the CRT 2.5i deployable boom technology and a concurrently developed deployment mechanism have been given and the strengths of each design have been discussed. CRT addresses many of the shortcomings of conventional spooling booms including inflatable, overlapping and lenticular varieties. However, the units discussed herein were built to satisfy the requirements of a 1-g spacecraft assembly demonstration rather than to push the limits of boom technology. Similarly, the deployment mechanism was designed for integration with preexisting robots operating in a laboratory environment and should be considered a prototype. All design, fabrication and demonstration activities related to this deployable system took place in less than one year.

\section{Acknowledgments}

This work was made possible through the support of the NASA Marshall Space Flight Center.

\section{References}

${ }^{1}$ LeMaster, E.A., Schaechter, D.B., and Carrington, C.K., "Experimental Demonstration of Technologies for Autonomous On-Orbit Robotic Assembly," in Proceedings of AIAA Space 2006, San Jose, CA, 2006.

${ }^{2}$ Bowden, M.L., "Deployment Devices," Space Vehicle Mechanisms, edited by P. Conley, John Wiley and Sons, New York, 1998, pp. 495-542.

${ }^{3}$ Rimrott, F.P.J., "Storable Tubular Extendible Member," Machine Design, No. 37, Dec. 9, 1965, pp. 156-165.

${ }^{4}$ MacNaughton, J.D., Weyman, H.N., and Groskopfs, E., "The BI-STEM - A New Technique in Unfurlable Structures," in Proceedings of the 2nd Aerospace Mechanisms Symposium, Santa Clara, CA, 1967, pp. 139-145.

${ }^{5}$ Sickinger, C., Herbeck, L., Ströhlein, T., and Torrez-Torres, J., "Lightweight Deployable Booms: Design, Manufacture, Verification, and Smart Materials Application," in Proceedings of 55th International Astronautical Congress, Vancouver, Canada, 2004.

${ }^{6}$ Herbeck, L., Eiden, M., Leipold, M., Sickinger, C., and Unckenbold, W., "Development and Test of Deployable UltraLightweight CFRP-Booms for a Solar Sail," in Proceedings of the European Conference on Spacecraft Structures, Materials and Mechanical Testing, Noordwijk, The Netherlands, 2000, pp. 107-112. 
${ }^{7}$ Iqbal, K. and Pellegrino, S., "Bi-Stable Composite Shells," in Proceedings of AIAA Structures 2000, Atlanta, Georgia, 2000. ${ }^{8}$ Del Campo, F. and Ruiz Urien, J.I., "Collapsible Tube Mast - Technology Demonstration Program," Space Technology, Vol. 13, No. 1, 1993, pp. 61-76.

9Sickinger, C., and Herbeck, L., "Deployment Strategies, Analyses and Tests for the CFRP Booms of a Solar Sail," in Proceedings of the European Conference on Spacecraft Structures, Materials and Mechanical Testing, Toulouse, France, 2002.

${ }^{10}$ Calladine, C.R., Theory of Shell Structures, Cambridge University Press, Cambridge, UK, 1983.

${ }^{11}$ Rimrott, F.P.J. and Fritzsche, G., "Fundamentals of STEM Mechanics," in Proceedings of the IUTAM-IASS Symposium on Deployable Structures: Theory and Applications, Cambridge, UK, 1998, pp. 321-333.

${ }^{12}$ Postma, R.W., "Torque Loss and Stress Relaxation in Constant Torque Springs," in Proceedings of the 38th Aerospace Mechanisms Symposium, Hampton, VA, 2006, pp. 163-168.

${ }^{13}$ Young, W.C. and Budynas, R.G., Roark's Formulas for Stress and Strain, $7^{\text {th }}$ ed., McGraw-Hill, New York, 2002. 